\title{
Automatic Control Unit for Air-Condition System in Building
}

\author{
Pairach Tanuphol ${ }^{1}$, Chaichan Pothisarn ${ }^{2}$ \\ ${ }^{1}$ Faculty of Engineering, Saint John's University, Bangkok, Thailand \\ ${ }^{2}$ Faculty of Engineering, King Mongkut's Institute of Technology Ladkrabang, Bangkok, Thailand
}

\begin{abstract}
Electrical energy usage has been rapidly increased in the building sector due to shifting in population from rural to urban area. In the building, Heating, ventilation, and air conditioning (HVAC) system. Especially aircondition system has taken the most substantial proportion of overall building energy consumption. This result from a large amount of energy must be used in order to provide a comfort zone for occupants in the building. So, this paper aims to proposed design and built prototypes of air-condition control unit that can automatically operate according to schedule. The prototypes using a wireless module to send the control signal to the air-conditioning unit. Specific software has been built to set the desired operating schedule and duration of an operation. The performance of the proposed unit will be evaluated using an experiment on actual field test by installing on actual air-condition in the case study building. The result has shown that the proposed unit can reduce energy usage in air-conditioning significantly compare with little cost for the controller unit.
\end{abstract}

\section{Introduction}

Sustainability of energy is one of the critical determinants of mobility and development in Thailand due to the high demand for energy from the growth of the economy and population. The trend in energy consumption is likely to be higher in the future. According to Thailand's energy consumption statistics for 2016, residential and commercial buildings account for $22 \%$ [1]. The government recognizes and convenes the energy saving policy and the 20-year energy development plan with the aim of reducing energy intensity with a share of $17.6 \%$ energy savings for the residential and commercial sectors [2]. The construction of a new building or renovation of the existing building with a total area of more than 2,000 square meters will be subject to government regulation, that is Building Energy Code (BEC), buildings that meet the six energy efficiency control requirements of BEC; building envelope, air-conditioning, lighting, hot water, renewable energy, and whole building energy usage will be able to complete the construction [3].

From the perspective of the Heating, ventilation, and air conditioning (HVAC) system in Thailand which locates in the tropical, has a hot and humid meteorological pattern, resulting the lifestyle of people needs the air conditioners [4]. The energy consumption for air conditioning systems is as high as 60 percent of total energy consumption in buildings. This paper focuses on energy efficiency improvement issues. The design of efficient air conditioning control circuits is presented.

HVAC systems are currently widely studied in control and energy management. According to the literature review, there are many pieces of research focusing on air conditioning systems., energy efficiency measured and technologies that applied to an air-conditioning system has been discussed [5]-[10]. In a study by B. Kul [5], the IP-based smart sensors for improving the energy efficiency of the HVAC systems for building, an output data provide the features operating to reduce energy loss. The experimentally studies in airflow, electrical, power consumption, EER, superheat and subcooling in the HVAC vapor compression cycle performed by V. Marian et al. [6]. B. Sajjad and Ulusoy I. proposed an intelligently consider the user comfort and energy efficiency to operate the HVAC energy applying Qlearning control method in [7]. The modeling and analysis of an HVAC system in the section of hot water and electrical consumption, the state space model, were identified in the study of A. Almahdi et al. [8]. The study in [9] by K. Vinay et al. illustrated the use of dynamic zones for efficient control of HVAC systems overcoming the limitations of static zones. Moreover, a framework for HVAC optimization and the regulated monitoring system with a graphical visualization of the real-time data has been provided by K. B. Priya and H. R. Sulbha in [10].

This paper proposed design and built a model of a control unit for air-conditioning system in the building. The actual prototype has been built, and analysis on field test has been done to evaluate the performance of proposed air-condition control unit in term of both operating accuracy and energy consumption. The result and methodology from case study able to other projected to improve energy efficiency in both existing and newly constructed building in the future. 


\section{Circuit Diagram}

Electronic circuit and equipment using in this proposed air-condition control unit consist of 4 part; Control computer, Control unit, Sending-end and Receiving-end wireless module. The diagram of the proposed aircondition unit is shown in Figure 1. From the Figure, the control unit can be operated by setting an operating schedule of air-conditioning in software that has been specifically designed. Command from software will be sent to the control unit via the wireless module, and then the control unit will be sent out a signal to operate aircondition.

\subsection{Wireless Module}

The wireless module has been used to send and receive a control signal from software to the control unit. MRF24J40MA wireless module has been used in the proposed control unit. The diagram of the wireless module is shown in Figure 2.

\subsection{Control Unit}

The microcontrollers in the AVR family has been used in the control unit. The layout of a microcontroller is shown in Figure 3(a) and the actual control unit that will be installed on air-condition is shown in Figure 3(b).

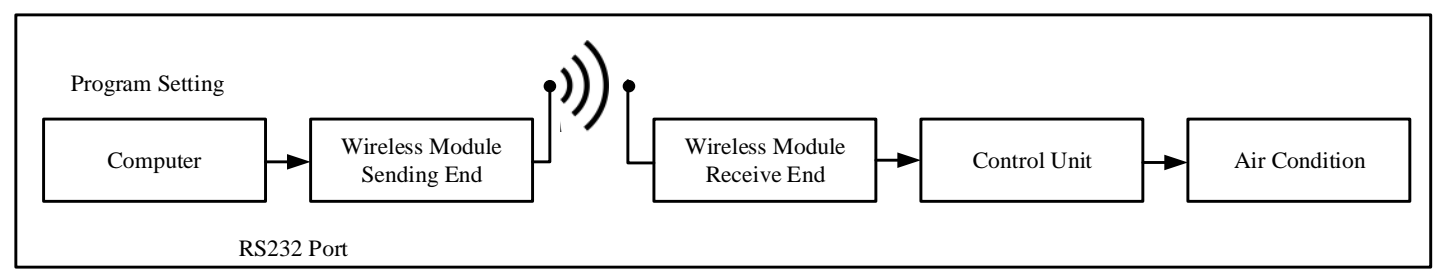

Figure 1. Diagram of proposed control unit

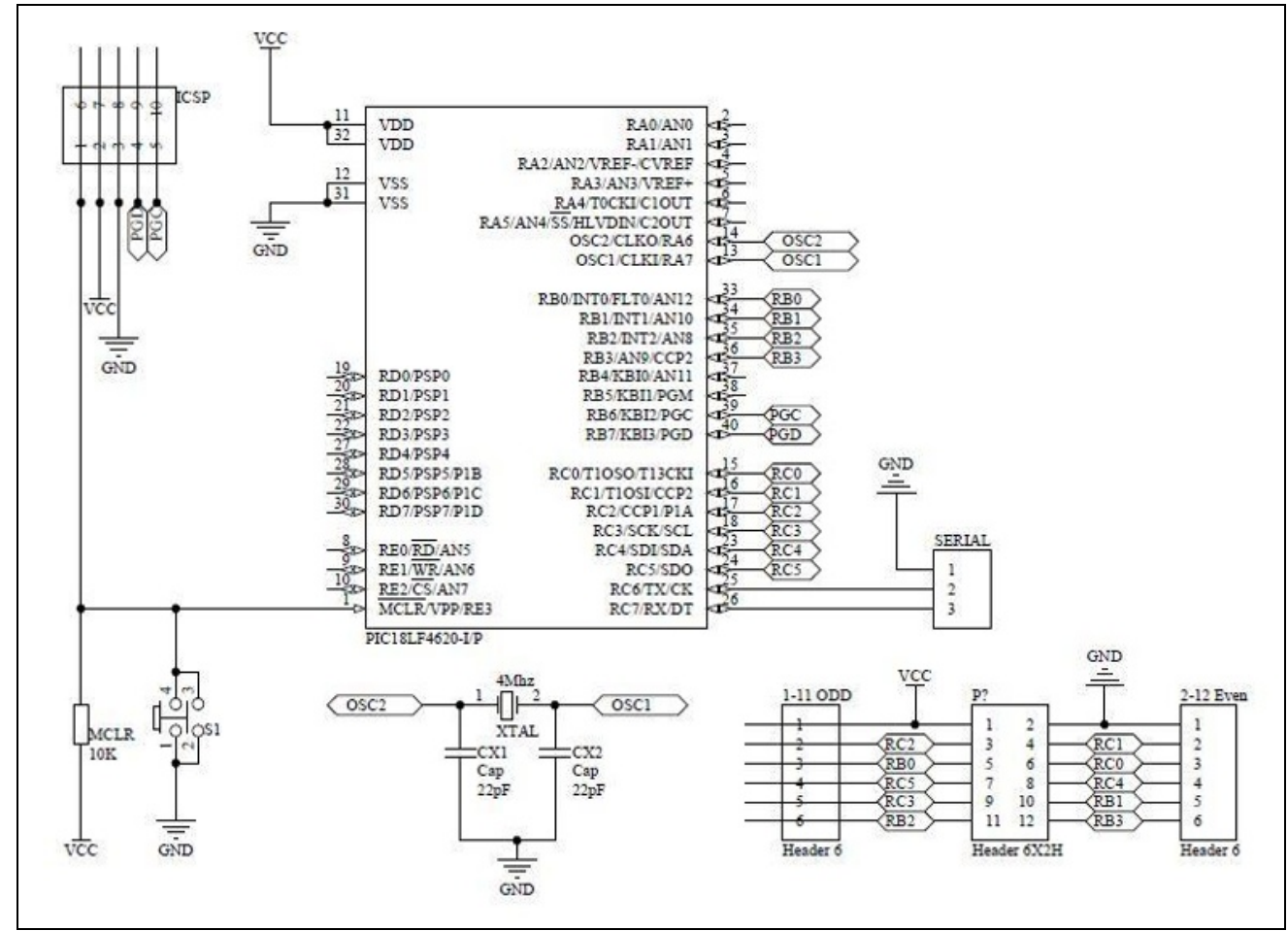

Figure 2. Diagram of Wireless Module MRF24J40MA 


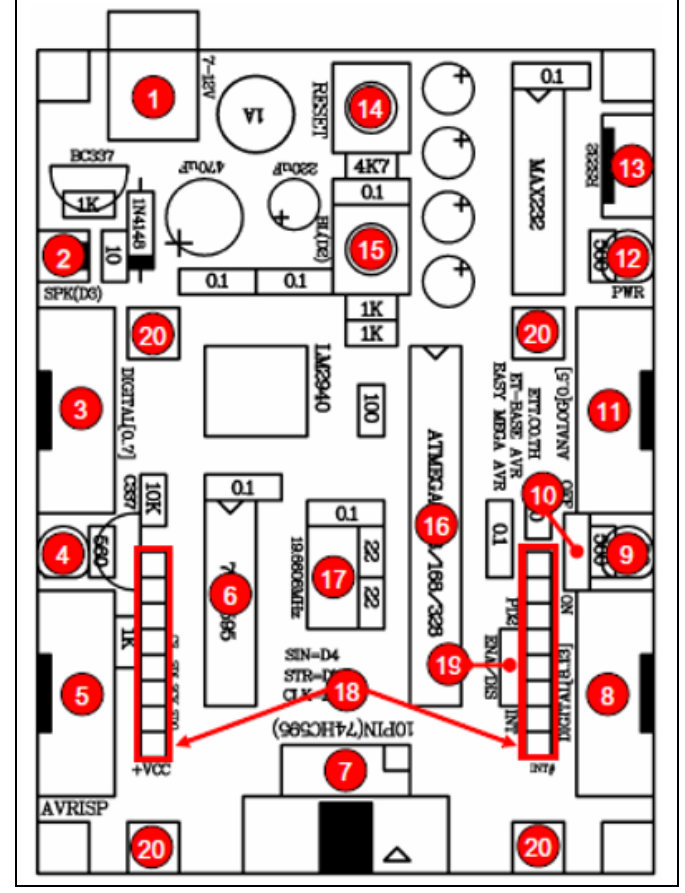

(a)

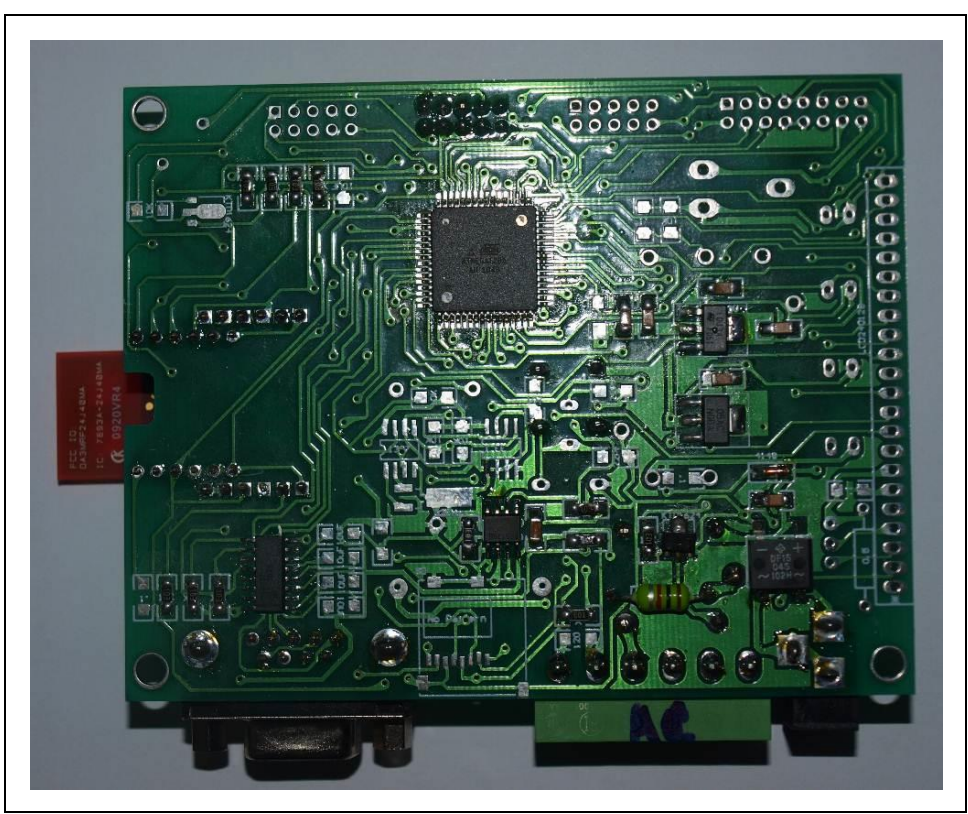

(b)

Figure 3. Microcontroller unit

\section{Result}

The prototypes of proposed air-condition control unit are evaluated its performance by installing into actual aircondition in the building. The Lecturer room in Thailand university with 8 air-conditioning unit has been select as a case study for a field test. The specification of currently used air-conditions in the building is shown in Table 1. Air-condition energy performance has been specified in term of power consumption, energy usage, and Energy Efficiency Ratio (EER) value.

Table 1. Specification of currently used air-condition.

\begin{tabular}{|c|c|c|c|}
\hline Size (BTU) & $\begin{array}{c}\text { Power } \\
\text { (kW) }\end{array}$ & $\begin{array}{c}\text { Energy } \\
\text { (kWh/year) }\end{array}$ & $\begin{array}{c}\text { Energy } \\
\text { Efficiency } \\
\text { Ratio } \\
\text { (EER) }\end{array}$ \\
\hline 20,000 & 3.53 & $6,77.6$ & 5.07 \\
\hline
\end{tabular}

The user interface of software design for operating air-condition control unit is shown in Figure 4. The user interface of prototypes software can control up to 8 aircondition units that can set operating time and duration of operation individually.

The case study room usage pattern is starting from 8:20 to $12: 00$ in the morning session and afternoon session starting from 12:40 to 14:40. Lecturer room usage has been used the same schedule throughout weekday. However, the actual air-condition operation according to survey reveal that normal operating period has been started from 7:30 to the end of the end due to the behaviour of an occupant. This result in wasteful energy consumption in air-conditions system. So, the proposed control unit has been installed. The room usage, operating schedule with and without control unit is shown in Figure 5.

From the result, it can be seen that the proposed aircondition unit can operate according to set automatically. The result from Figure 5 confirms that the control unit can reduce air-condition operate time by 2 hours per day, thus reducing energy consumption and energy cost. The summarize of energy performance before and after installed control unit in air-conditions shown in Table 2.

Table 2. Energy usage before and after installed control unit.

\begin{tabular}{|c|c|}
\hline Number of Air-Condition (unit) & 8 \\
\hline Current Energy usage per day (kwh) & 26.475 \\
\hline New Energy usage per day (kw) & 19.062 \\
\hline Power Reduction (kw) & 7.413 \\
\hline Annual Energy Saving (kWh/yrs.) & $1,934.79$ \\
\hline
\end{tabular}




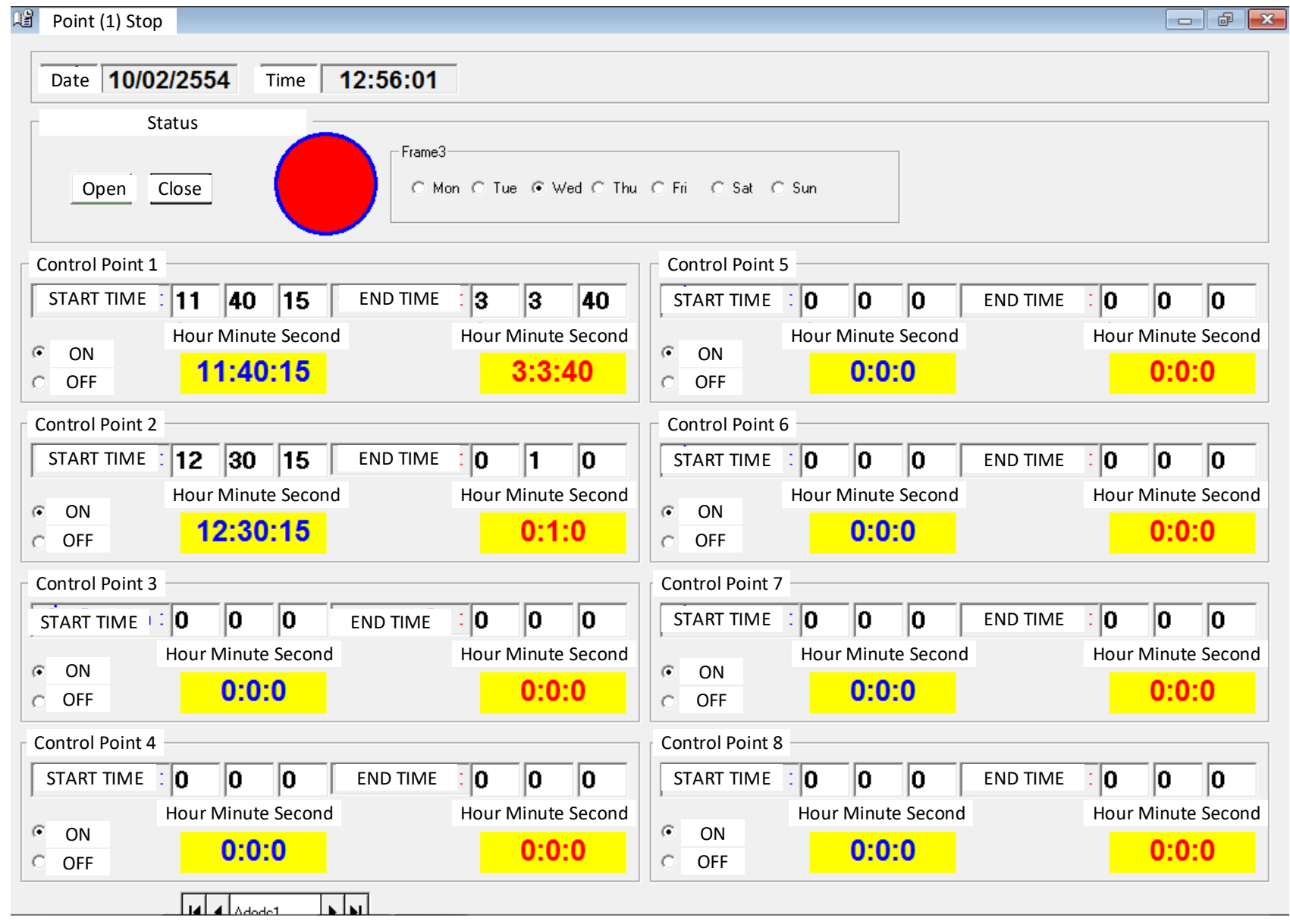

Figure 4. Software user interface for Air-condition control unit.

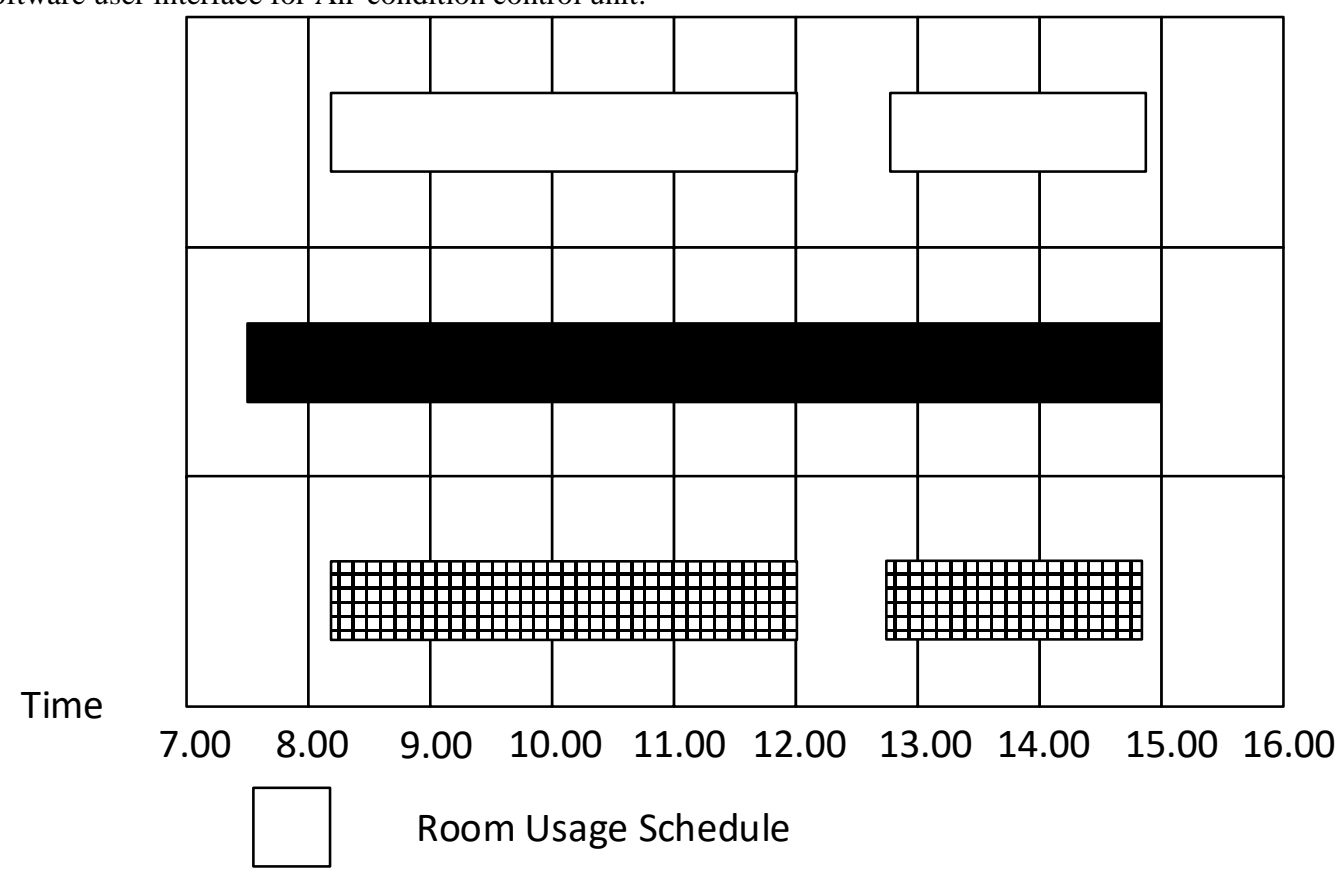

Normal Operating Period

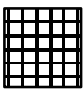

Operating Period with Control Unit

Figure 5. Air-condition usage and actual operating schedule 


\section{Conclusion}

This Paper proposed control circuit that can operate aircondition automatically according to the set schedule. The result of an experiment on actual field test has shown that the proposed air-condition unit can reduce energy consumption in the air-conditioning system by 1,934 $\mathrm{kWh}$ annually compare to the air-conditioning system without control unit. The reduction of energy usage contributes from reducing operating hour per day by planning and automatically operate air-condition strict to schedule. Research result and prototypes unit can be applied to both currently used, and newer air-condition to improve building energy efficiency in the future.

\section{Acknowledgment}

The authors wish to gratefully acknowledge financial support for this research from Faculty of Engineering, King Mongkut's Institute of Technology Ladkrabang Research fund, Thailand.

\section{References}

1. Energy Policy and Planning office (EPPO), "Energy Statistics of Thailand 2016," Energy Policy and Planning Office, Ministry of Energy of Thailand, 2016.

2. Ministry of Energy, "Thailand 20-Year Energy Efficiency Development Plan (2011-2030)," Energy Policy and Planning Office, Ministry of Energy of Thailand, 2011.

3. The Energy Conservation Promotion Act B.E. 2535, 1992.

4. Department of Alternative Energy Development and Efficiency (DEDE), "Research and
Development in the field of Energy Conservation and Renewable Energy in Thailand," Department of Alternative Energy Development and Efficiency, Ministry of Energy, 2012

5. B. Kul, "IP-based smart sensors for energy metering and efficient HVAC infrastructure in buildings," 2017 15th International Conference on Electrical Machines, Drives and Power Systems (ELMA), Sofia, pp. 258-261, 2017.

6. M. Voinea, H. Necula and I. Bitir-Istrate, "Aspects regarding fouling of the heat exchanger coils and filters on the performance of packaged air to air HVAC system," 2017 International Conference on ENERGY and ENVIRONMENT (CIEM), Bucharest, pp. 167-171, 2017.

7. S. Baghaee and I. Ulusoy, "User comfort and energy efficiency in HVAC systems by Qlearning," 2018 26th Signal Processing and Communications Applications Conference (SIU), Izmir, pp. 1-4, 2018.

8. A. Abdo-Allah, T. Iqbal and K. Pope, "Modeling and analysis of an HVAC system for the S.J. Carew Building at Memorial University," 2017 IEEE 30th Canadian Conference on Electrical and Computer Engineering (CCECE), Windsor, ON, pp. 1-4, 2017.

9. V. Kumar, R. Kumar, D. Patkar and A. S. Bopardikar, "A method to identify dynamic zones for efficient control of HVAC systems," 2017 IEEE International Symposium on Circuits and Systems (ISCAS), Baltimore, MD, pp. 1-4, 2017.

10. P. B. Karhade and S. R. Hawa, "Optimisation of HVAC system using programmable controllers and data acquisition," 2016 International Conference on Internet of Things and Applications (IOTA), Pune, pp. 254-258, 2016. 